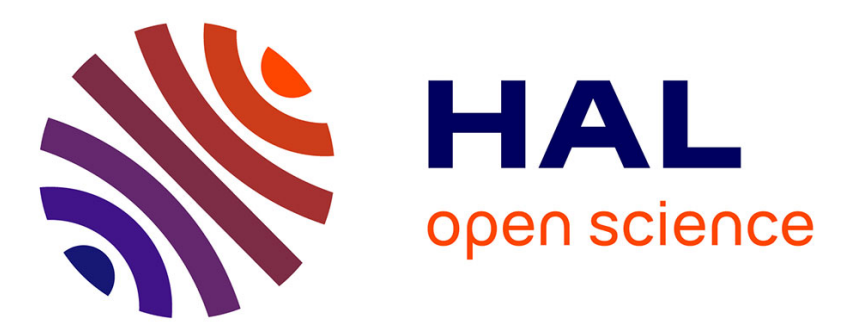

\title{
A coupling procedure for modeling acoustic problems using finite elements and boundary elements
}

\author{
J. Coyette, G. Vanderborck, W. Steichen
}

\section{To cite this version:}

J. Coyette, G. Vanderborck, W. Steichen. A coupling procedure for modeling acoustic problems using finite elements and boundary elements. Journal de Physique IV Proceedings, 1994, 04 (C5), pp.C5-331-C5-334. 10.1051/jp4:1994568 . jpa-00253063

\section{HAL Id: jpa-00253063 https://hal.science/jpa-00253063}

Submitted on 1 Jan 1994

HAL is a multi-disciplinary open access archive for the deposit and dissemination of scientific research documents, whether they are published or not. The documents may come from teaching and research institutions in France or abroad, or from public or private research centers.
L'archive ouverte pluridisciplinaire HAL, est destinée au dépôt et à la diffusion de documents scientifiques de niveau recherche, publiés ou non, émanant des établissements d'enseignement et de recherche français ou étrangers, des laboratoires publics ou privés. 


\title{
A coupling procedure for modeling acoustic problems using finite elements and boundary elements
}

\author{
J.P. COYETTE, G. VANDERBORCK* and W. STEICHEN*
}

Numerical Integration Technologies, Ambachtenlaan 11 A, 3001 Leuven, Belgium

* Thomson-Sintra ASM, 525 route des Dolines, BP. 157, 06903 Sophia-Antipolis cedex, France

\begin{abstract}
Finite element (FEM) and boundary element (BEM) methods have been used for a long time for the numerical simulation of acoustic problems. The development presented in this paper deals with a general procedure for coupling acoustic finite elements with acoustic boundary elements in order to solve efficiently acoustic problems involving non homogeneous fluids. Emphasis is made on problems where finite elements are used for a confined (bounded) fluid while boundary elements are selected for an external (unbounded) fluid. The discrete sets of equations related to the two models are first summarized. An elimination procedure is then proposed for solving the coupled problem. This procedure enables to take care of the sparseness of the finite element matrix and leads to solve an updated boundary element system. The solution sequence allows for the treatment of multiple load cases (velocity boundary conditions) in order to generate mutual impedance coefficients.
\end{abstract}

\section{PROBLEM'S STATEMENT}

The problem to be solved involves (at least) two fluid regions with different acoustic properties (Figure 1). The first fluid region $\left(\Omega_{\mid}\right)$is assumed to be bounded. His acoustic properties are $\rho_{I}$

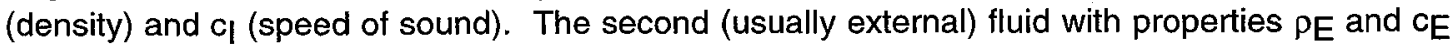
occupies the region $\left(\Omega_{E}\right)$ and shares a common interface $\left(\Gamma_{E C}\right)$ with the first region.

On this interface, acoustic pressures and velocities have to respect the continuity constraints:

$\mathrm{p}\left(\mathrm{X}^{-}\right)=\mathrm{p}\left(\mathrm{X}^{+}\right) \quad \forall \mathrm{X} \in \Gamma_{\mathrm{EC}}$

$\mathrm{v}_{\mathrm{n}}\left(\mathrm{X}^{-}\right)=\mathrm{v}_{\mathrm{n}}\left(\mathrm{X}^{+}\right) \quad \forall \mathrm{X} \in \Gamma_{\mathrm{EC}}$

where $\mathrm{X}^{-}$and $\mathrm{X}^{+}$are points along boundary $\Gamma_{\mathrm{EC}}$ inside $\Omega_{\mid}$and $\Omega_{\mathrm{E}}$ respectively.

Additionally pressure, normal velocity and/or normal admittance boundary conditions can be constrained along the boundaries $\Gamma_{\mid}$and $\Gamma_{E U}$. The acoustic response inside region $\Omega_{\mid}$and/or $\Omega_{E}$ has to be evaluated in some frequency range taking into account radiation into the external region. Several unit velocity boundary conditions have to be considered in order to generate transfer functions related to sub-surfaces located on $\Gamma_{\boldsymbol{l}}$.

\section{FEM AND BEM MODELS}

The solution within the bounded region $\Omega_{\mid}$is obtained using the acoustic finite element method [1] with a conventional pressure formulation. The discretization process allows to relate the nodal 
pressure vector $P$ to the fixed velocity vector $\bar{V}_{n}$ (along a part of $\Gamma_{l}$ ) and the unknown velocities $V_{n}^{\prime}$ (along $\Gamma_{E C}$ ):

$\left[K-i \omega A_{n}-\omega^{2} M\right](P)=i \omega\left[C_{1}\right]\left(\bar{V}_{n}\right)+i \omega\left[C_{E}\right]\left(V_{n}^{\prime}\right)$

where the matrices $K$ and $M$ are the usual stiffness and mass matrices while the matrix $A_{n}$ contains admittance values related to some part of $\Gamma_{\Gamma}$.

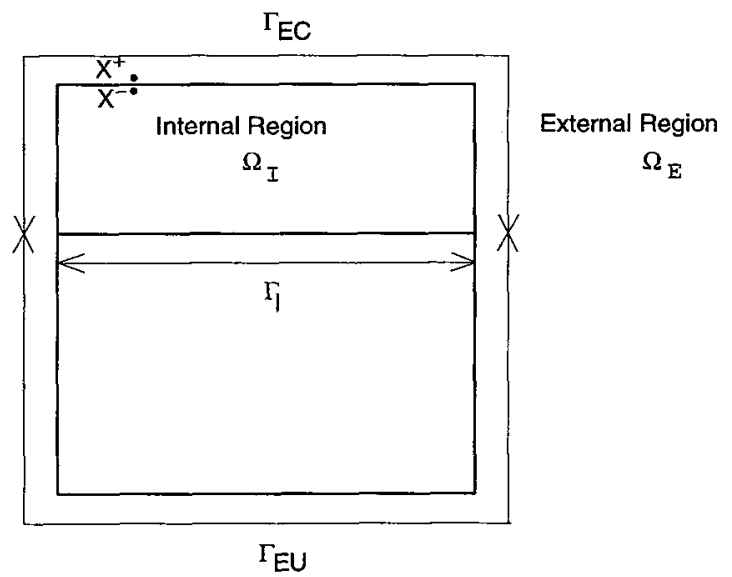

Figure 1 : Basic geometry of the fluid domain.

Within the external unbounded region $\Omega_{E}$, the discrete solution can be evaluated from a direct boundary element model [2] leading to a set of relations between nodal pressures $P_{E}$ and nodal normal velocities $V_{n}^{E}$ along the closed boundary $\Gamma_{E}$ :

$[A]\left(P_{E}\right)=[B]\left(V_{n}^{E}\right)$

where A and B are complex, frequency dependent, fully populated, non-symmetric matrices.

\section{COUPLING STRATEGY}

The global acoustic problem results from combination of systems (3) and (4) taking into account the continuity constraints (1) and (2).

These constraints can be rewritten for the discrete model as:

$\left(P_{E C}\right)=[F](P)$

$\left(V_{n}^{E C}\right)=-\left(V_{n}^{\prime}\right)$

where $F$ is a Boolean matrix allowing to extract the sub-vector $P_{E C}$ of $P_{E}$ from the global vector $P$. The velocity vector $V_{n}^{E C}$ is a sub-vector of $V_{n}^{E}$. Note that the minus sign in (6) is due to the different normal orientations along the boundary $\Gamma_{E C}$.

Systems (3) and (4) can be merged into the coupled system: 
$\left[\begin{array}{cc}Z & i \omega \tilde{C}_{E} \\ \tilde{A} F & -\tilde{B}\end{array}\right]\left(\begin{array}{l}P \\ T\end{array}\right)=\left(\begin{array}{c}i \omega R \\ S\end{array}\right)$

where

$Z=K-i \omega A-\omega^{2} M$

$\mathrm{R}=\mathrm{C}_{1} \cdot \overline{\mathrm{V}}_{\mathrm{n}}$

while $\tilde{A}, \tilde{B}$ and $\tilde{C}_{E}$ result from rearrangements of $A, B$ and $C_{E}$ matrices and vector $T$ contains the remaining unknowns along the boundary surface.

Solution of system (7) will give the nodal pressures within the finite element region and the additional boundary variables along the surface $\Gamma_{E}$.

\section{SOLUTION PROCEDURE}

An efficient solution procedure has to take care of the characteristics of the various matrices involved in the coupled system (7).

The matrix $Z$ which results from the finite element model is symmetric and sparse. This matrix can be generated easily from element stiffness, mass and damping matrices at any specified frequency. The matrix $\tilde{C}_{E}$ is a real matrix which depends only on the geometry. The sub-matrices of $\tilde{A}$ and $\tilde{B}$ are complex, non-symmetric and fully populated. They need to be computed for each specified frequency. The order of these matrices is usually smaller than the order of the $Z$ matrix.

Because of these characteristics, the solution scheme is subdivided in three steps. Step 1 deals with the elimination of nodal FE pressures, step 2 consists to solve the updated BE problem while step 3 is related to the recovery of nodal pressures within the FE region. The main advantage of the proposed solution procedure is related to the effective consideration of the sparseness of finite element equations. Note that the handling of different load cases is straightforward in this solution procedure. Each additional load case at a given frequency requires to solve the FEM system with a new right hand side. The additional computing time for such a treatment is only marginal.

\section{NUMERICAL APPLICATION}

The studied problem is related to the evaluation of the performances of a torpedo array where the coupling between transducers (Figure 2) is decomposed into two parts: (a) elastic coupling due to shear waves and (b) radiative coupling due to compressional waves. This decomposition is further commented in [3]. In the present application, the so-called 'acoustic window' (elastic cover material) is considered as a fluid with equivalent material properties.

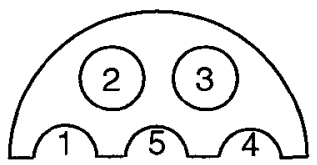

Figure 2 : Schematic layout of the transducers. 
A unit velocity boundary condition is considered along the central transducer ( $\mathrm{N}^{\circ} 5$ in Figure 2). From the discrete solution on the boundary surface, the directivity diagram in a vertical plane can be generated (Figure 3).

\section{CONCLUSIONS}

A refined procedure [4] has been developed in order to handle multi-fluid acoustic problems. The technique relies on the use of a (pressure) FE method (allowing to handle bounded fluids) coupled to a direct BE method (for both interior or exterior homogeneous fluids). The solution is obtained through a staggered procedure where FE variables are first eliminated taking into account the sparseness of the finite element coefficient matrix. The updated boundary element system is then solved for the various load cases.

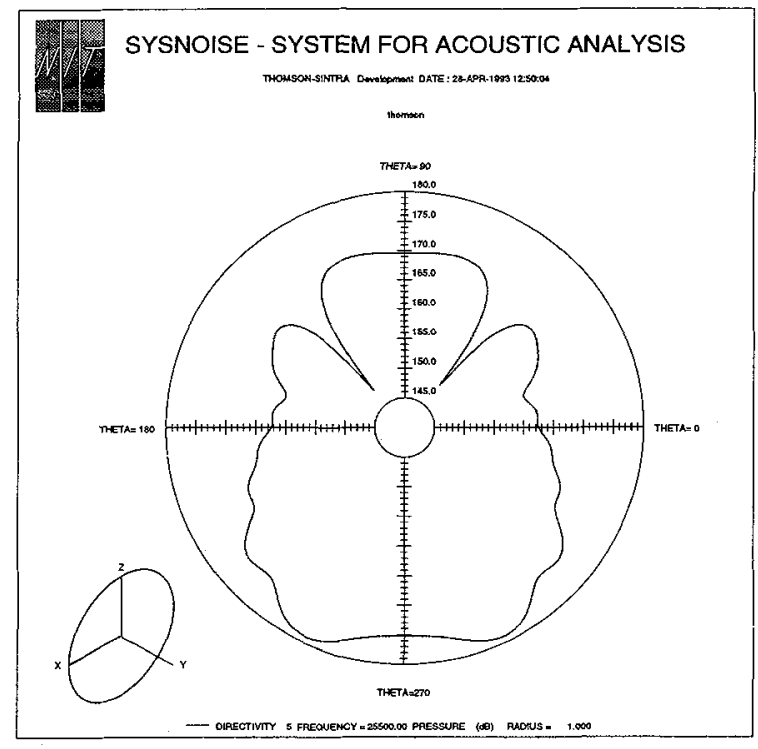

Figure 3 : Directivity diagram (pressure) in a vertical plane.

\section{REFERENCES}

[1] Craggs A., The use of simple three-dimensional acoustic finite elements for determining the natural modes and frequencies of complex shaped enclosures, Journal of Sound and Vibration, 23 (1972) 331-339.

[2] Schenck H.A., Improved integral formulation for acoustic radiation problems, J. Acoust. Soc. Am., 44 (1968) 41-58.

[3] Steichen W., Vanderborck G. and Coyette J.P., Numerical evaluation of acoustic interactions between transducers, INTERNOISE'93 Conference, Leuven (1993) 225-230.

[4] AMFIBIE (Acoustic Modeling Through Finite Element Integration with Boundary Integral Equations), User's Manual, Numerical Integration Technologies, Leuven (1993) 